
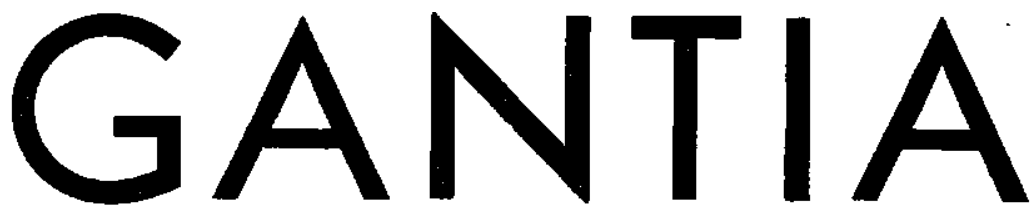

Boletim Técnico do Instituto Agronômico do Estado de São Paulo

Vol. 16

Campinas, outubro de 1957

N. 1

\title{
DISTRIBUIÇÃO DO SISTEMA RADICULAR DA CANA DE AÇÚCAR VAR. Co. 290, EM SOLO TIPO TERRA-ROXA-LEGITIMA (*)
}

ROMEU INForzato, engenheiro-agrônomo, Seçâo de Fisiologia e RAPHAEL Alvarez, engenheiro-agrônomo, Seção de Cana de Açúcar, Instituto Agronômico

\section{RES U M O}

No presente trabalho são apresentados os resultados obtidos no estudo do sistema radicular da cana de açúcar var. Co. 290, sob condiçóes normais de cultivo em terra-roxa-legítima, na Usina Tamóio, município de Araraquara e em três idades: seis, doze e dezoito meses. Empregou-se o mesmo método já utilizado para o cafeeiro, com as alteraçōes convenientes à cana de açúcar.

Os resultados mostraram que a distribuição do sistema radicular da variedade estudada se apresentou bem homogênea nas diferentes camadas de solo, sendo que o maior adensamento se deu nos primeiros $30 \mathrm{~cm}$ com uma média, nas três idades, de $59,3 \%$.

Observou-se que aos seis meses as raízes iam além de $2,10 \mathrm{~m}$ de profundidade, para atingir $3,30 \mathrm{~m}$ na planta adulta. O máximo de raízes vivas foi encontrado aos 12 meses, periodo de intenso crescimento da planta.

Calculou-se a quantidade de raizes que essa cultura deixa incorporada ao solo, após o corte. Para uma produção de 100 toneladas de cana por hectare a planta, aos seis meses, já fornece 1,8 toneladas de raízes nessa mesma área, atingindo a 8 toneladas na planta adulta.

\section{1 - INTRODUÇÃO}

A cana de açúcar é cultivada no Estado de São Paulo sob condições as mais diversas, porém sua produção por área deixa muito a desejar. Nestes últimos anos a cultura tomou grande desenvolvimento, situando-se entre as principais do Estado e ocupando uma área de 216.627 hectares (1). Muitos e complexos são os fatôres que influem na produtividade daquela planta. Se pouco ou nada pode fazer o agricultor para modificar as condições de calor,

(*) Os autores expressam seus agradecimentos aos Srs. Hélio Morganti, Diretor-Gerente, e Engs. Agrs. A. C. Penteado e J. Polezzi, pelas facilidades proporcionadas na Usina Tamôio, para a realizaçâo do presente trabalho; aos colegas da Seçâo de Agrogeologia, peías análises físico-químicas apresentadas no quadro 2; ao Eng. Agr. Hernani Godoy, Chefe da Seção de Climatologia Agrícola, pelo fornecimento dos dados do quadro 1.

Recebido para publicação em 18 de junho de 1956. 
Iuz e umidade do ar, pode, entretanto, influir notàvelmente sôbre a estrutura, a fertilidade, a aeração e umidade do solo, mediante o cultivo, adubação e irrigação apropriados. 0 conhecimento exato do desenvolvimento e distribuição das raízes e do seu comportamento sob as condições normais de cultivo, é de grande valor prático (9).

Assim, antes de dar soluções a problemas como o do preparo do solo, do método de aplicação de adubos, da quantidade e aplicação da água de irrigação, do tipo de cultivo etc., é de grande importância o conhecimento da forma que as raízes tomam devida às propriedades do solo em que se desenvolvem, e a posição que ocupam, em diferentes idades da planta.

Entre os fatôres que mais influem no desenvolvimento do sistema radicular, destacam-se a riqueza em elementos minerais, o teor de umidade e a aeração do solo. A influência dêsses fatôres foi estudada e claramente exposta por Weaver (8) e Weaver e Clements (9), e, no caso particular da cana de açúcar, por outros autores $(4,5,7)$.

Lee, em uma série de trabalhos em que estudou a distribuição das raízes da cana nos solos das Ilhas Havaianas, verificou que a maioria das raízes se encontrava nas primeiras oito polegadas do solo, e que $85 \%$ se encontravam até 24 polegadas de profundidade (5). De posse dos resultados, concluiu que a aeração do solo constitui o principal fator para que as raízes da cana tenham boa superfície de absorção. Devido a isso, preconiza aração profunda antes do plantio, e, em seguida, incorporação de matéria orgânica nas camadas inferiores. Diz ainda que as culturas canavieiras das Ilhas Havaianas se processam sem rotação de cultura e com pequenos intervalos de descanso. Isto deu motivo para se indagar até quando a cultura pode ser feita sem prejudicar a sua produção. A resposta freqüente é a de que as raízes da cana provêm o solo de matéria orgânica, sendo menos necessárias as práticas de rotação e descanso. Baseando-se nas quantidades de raízes encontradas para as culturas irrigadas do Hawaii, calculou que elas fornecem de 900 a $1.850 \mathrm{~kg}$ de matéria orgânica sêca, por acre.

Jensen estudou o sistema radicular de nove variedades de cana, em dois tipos de solo de Cuba (4). Os estudos foram feitos com plantas de 4, 6, 10 e 11 meses de idade. Verificou que as variedades diferem pouco na distribuiçãa de suas raízes, e que tôdas emitem uma grande quantidade de raízes perto da superfície do solo. Em todos os casos estudados, mais de 50\% de raízes de uma planta madura foram encontrados nas primeiras oito polegadas de solo. 
De nosso conhecimento, nenhum estudo sôbre êsse assunto existia entre nós. Com o objetivo de obter elementos mais positivos para o nosso meio, os autores planejaram o estudo do sistema radicular da cana de açúcar var. Co. 290, sob as condições normais de cultivo, nos principais tipos de solo em que se situa a lavoura canavieira do Estado de São Paulo.

Preliminarmente o trabalho foi realizado em terra-roxa-legitima, a qual detém a maior parte de área com essa gramínea.

O estudo dá uma idéia do hábito das raízes em três idades da planta, mostrando o seu desenvolvimento, profundidade atingida e distribuição por camada de solo.

\section{2 - MATERIAL E METODO}

O estudo do sistema radicular da cana de açúcar em terra-roxa foi iniciado em agôsto de 1954, na Usina Tamôio, município de Araraquara.

As condições locais de clima durante o período em que foi realizado o presente estudo, estão resumidas no quadro 1 .

QUADro 1.-Dados pluviométricos e médias mensais de temperaturas na Usina Tamôio, nos anos de 1954-1955.

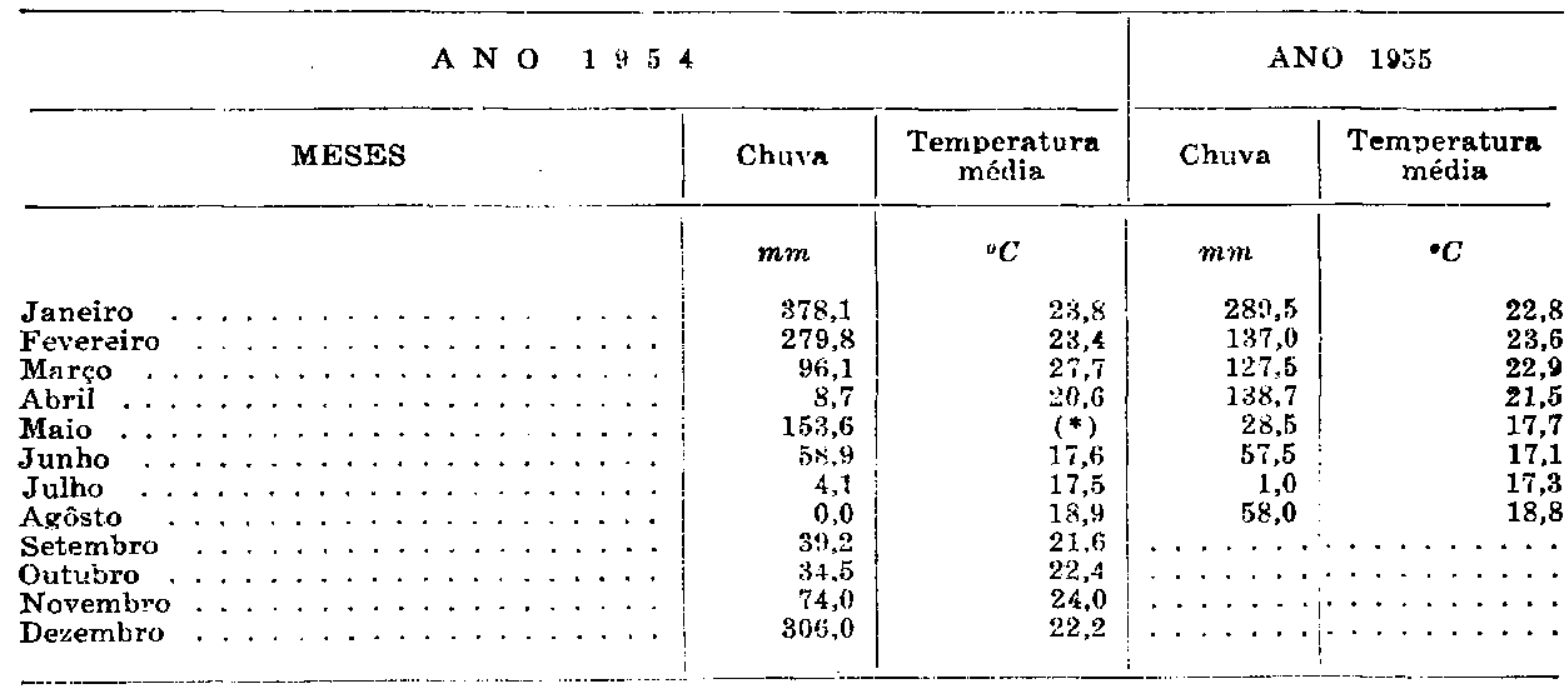

(*) A leitura correspondente ao mês de maio de 1954 năo foi feita.

As terras-roxas são das melhores para o cultivo da cana de açúcar, entre nós. Provenientes de rochas diabásicas, são profundas, porosas, e quando novas, de grande fertilidade (6). O estudo foi realizado em terra já cultivada há alguns anos com cana, e as suas principais características químicas e mecânicas são apresentadas no quadro 2. 


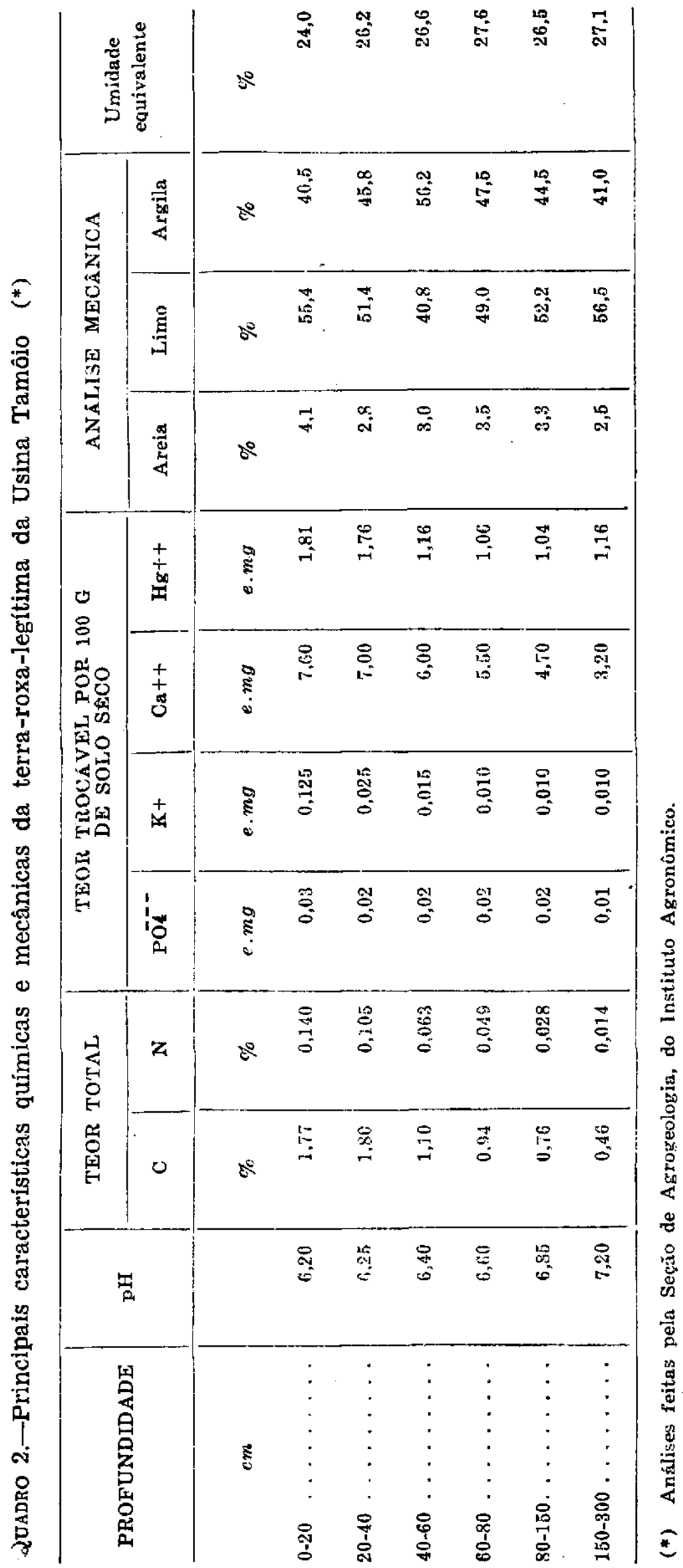


O preparo do terreno, sulcamento, plantio e tratos culturais foram realizados como se faz normalmente na grande cultura. Os níveis dos fertilizantes empregados foram, respectivamente, de $30-90-60 \mathrm{~kg} / \mathrm{ha}$ de $\mathrm{N}, \mathrm{P}$ e $\mathrm{K}$. O nitrogênio foi empregado sob a forma de sulfato de amônio, o fósforo sob a forma de farinha de ossos degelatinados e o potássio, como cloreto. A adubação foi realizada nos sulcos, por ocasião do plantio.

O talhão escolhido para estudo tinha recebido em cobertura, logo após nascida a cana, $15 \mathrm{t} / \mathrm{ha}$ de composto feito com palhaça de cana, na própria lavoura.

Escolheu-se a variedade Co. 290 por ser a inais cultivada e devido à sua boa adaptação a todos os tipos de solos em que se situa a lavoura canavieira paulista. No plantio foram utilizadas mudas selecionadas, provenientes de viveiros, com a idade de 10 meses.

A área escolhida para o trabalho tinha sido plantada em meados de fevereiro e estudou-se o sistema radicular em três idades da planta: aos 6, 12 e 18 meses. Nas duas primeiras idades foi estudado até a profundidade de $2,10 \mathrm{~m}$, e na terceira, até onde não houvesse mais raízes; considerou-se sòmente o pêso das raízes, excluindo-se o dos toletes.

$O$ estudo foi realizado em $2 \mathrm{~m}$ de sulco. Nesta extensão marcou-se a largura de $60 \mathrm{~cm}$, sendo $30 \mathrm{~cm}$ de cada lado da linha, a contar do centro do sulco.

O método empregado foi o mesmo usado para o cafeeiro (2), variando-se apenas o tamanho dos blocos de terra contendo as raízes, os quais tiveram as seguintes dimensões: nas três primeiras camadas de solo: $10 \times 40 \times 60 \mathrm{~cm}$, respectivamente para a altura, comprimento e largura; nas camadas restantes: $20 \times 40 \times 60 \mathrm{~cm}$.

Escolhida a linha de plantas representativa da cultura, cortouse a parte aérea, e, em seguida, abriu-se uma valeta lateralmente à mesma. Feito isto, retiraram-se os blocos de terra, cada um dêstes recebendo um número, para identificar a sua localização. Em seguida, foram acondicionados em sacos de pano e levados para um local apropriado, onde se fêz a separação das raízes; estas foram lavadas, sêcas ao ar e finalmente pesadas em balança sensível a centésimo de grama. Depois de anotados os seus pesos, as raízes foram distribuídas em uma prancha de madeira pintada de branco e riscada de acôrdo com a localização original dos blocos no solo, sendo as mesmas aí fotografadas.

\section{3 - RESULTADOS E DISCUSSÃO}

Os resultados apresentados no quadro 3 referem-se à distribuição em pêso, por camada de solo, do sistema radicular da variedade Co. 290, aos 6, 12 e 18 meses, cada camada compreendendo a soma de 5 blocos; os dados correspondem ao material retirado de uma parede de $60 \mathrm{~cm}$ de espessura, até a profundidade de $2,10 \mathrm{~m}$, abrangendo 2 metros da linha de plantas. 


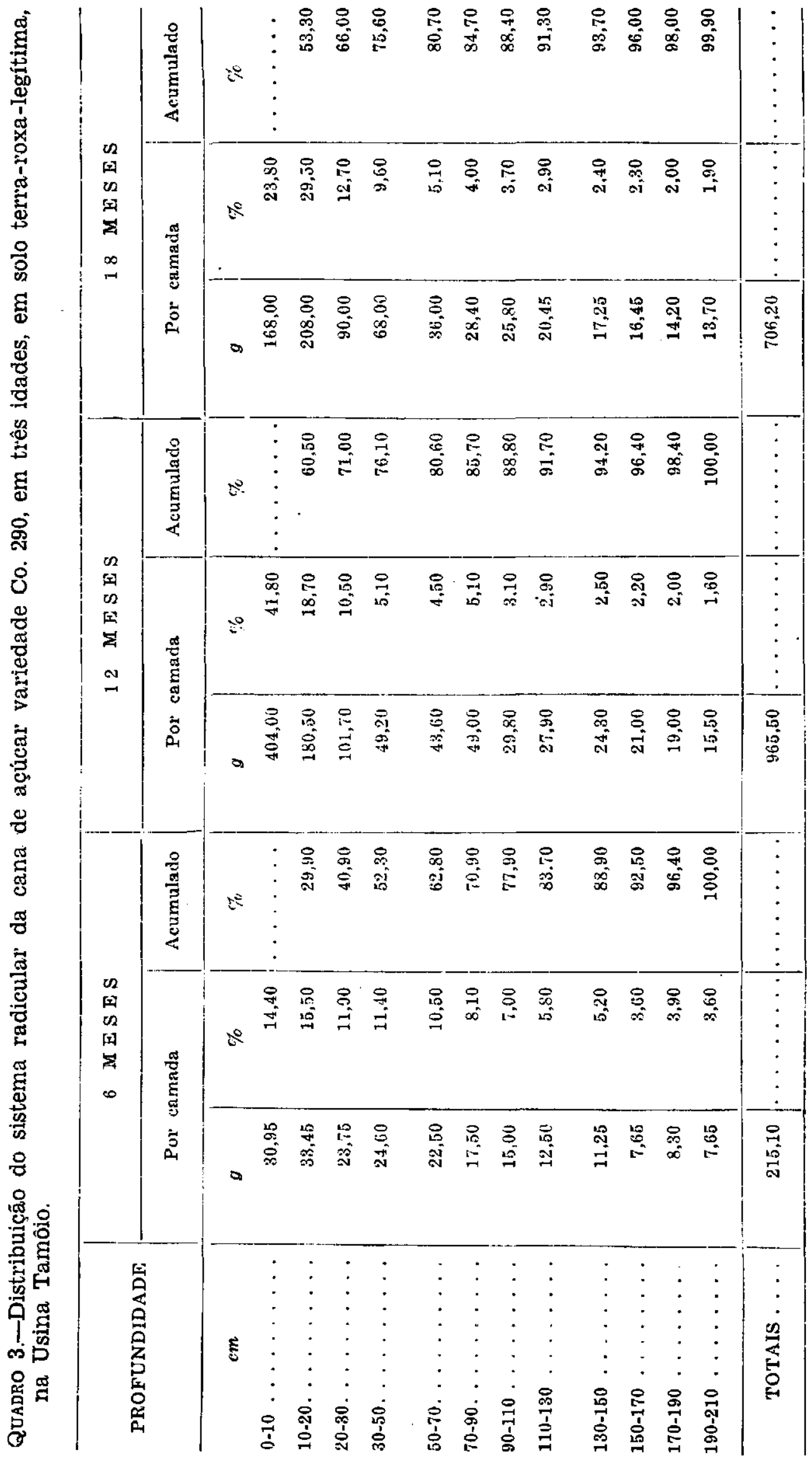




\section{1 - SISTEMA RADICULAR AOS 6 MESES}

A melhor época para plantio da cana de açúcar no Estado de São Paulo vai de janeiro a março. Escolheu-se para o estudo do sistema radicular dessa planta, que se iniciou em fins de agôsto, um plantio realizado em meados de fevereiro.

Inicialmente era intenção dos autores, neste primeiro trabalho, retirar os blocos até onde não houvesse mais raízes. Entretanto, chegando à profundidade de $2,10 \mathrm{~m}$, consideraram-na suficiente para observar a variação das raízes pelas camadas do solo, principalmente nas primeiras, o que orientaria posteriormente as práticas agrícolas para a cultura.

Êste primeiro trabalho corresponde a uma época sêca e relativamente fria (quadro 1). Apesar dessas condições desfavoráveis para a cultura da cana, as plantas estavam com bom aspecto, e após o corte rente ao chão, a parte aérea apresentou o pêso de 13,40 $\mathrm{kg}$, para $2 \mathrm{~m}$ de linha.

Foram extraídos 60 blocos de terra, representados por 12 camadas (quadro 3).

Como se observa pelos dados do referido quadro e a figura $1-A$, as raízes da cana aos 6 meses já ultrapassavam a profundidade de $2,10 \mathrm{~m}$. Verificou-se ainda que a sua distribuição foi muito boa em tôdas as camadas estudadas. O seu pêso foi diminuindo gradativamente à medida que se ia aprofundando no solo. A profundidade alcançada pelas raízes e a sua boa distribuição, esclarecem o bom aspecto apresentado pela parte aérea nos períodos de sêca.

$O$ pêso total de raízes foi de $215,10 \mathrm{~g}$, para um volume de terra de $2,00 \times 0,60 \times 2,10 \mathrm{~m}=2,520 \mathrm{~m}^{3}$. Esse pêso corresponde a 1,8 toneladas de raízes por hectare. A maioria das raízes foi encontrada até a profundidade de $70 \mathrm{~cm}$, com um pêso de $135,25 \mathrm{~g}$, correspondendo a $62,8 \%$ do total. Nos primeiros $30 \mathrm{~cm}$ de solo encontraram-se $88,15 \mathrm{~g}$, correspondendo a $40,9 \%$.

\section{2 - SISTEMA RADICULAR AOS 12 MESES}

O segundo estudo do sistema radicular foi realizado nos primeiros dias de março de 1955. De agôsto a março a cana de açúcar passou de uma época sêca e relativamente fria, para um período quente e chuvoso. Êste segundo trabalho foi realizado após a planta ter recebido quase tôdas as chuvas de verão. Cortadas as plantas rente ao solo, a parte aérea pesou $32,80 \mathrm{~kg}$, para $2 \mathrm{~m}$ de linha.

Este estudo, como o primeiro, foi realizado até a profundidade de $2,10 \mathrm{~m}$ e os dados obtidos se encontram também no quadro 3 . 


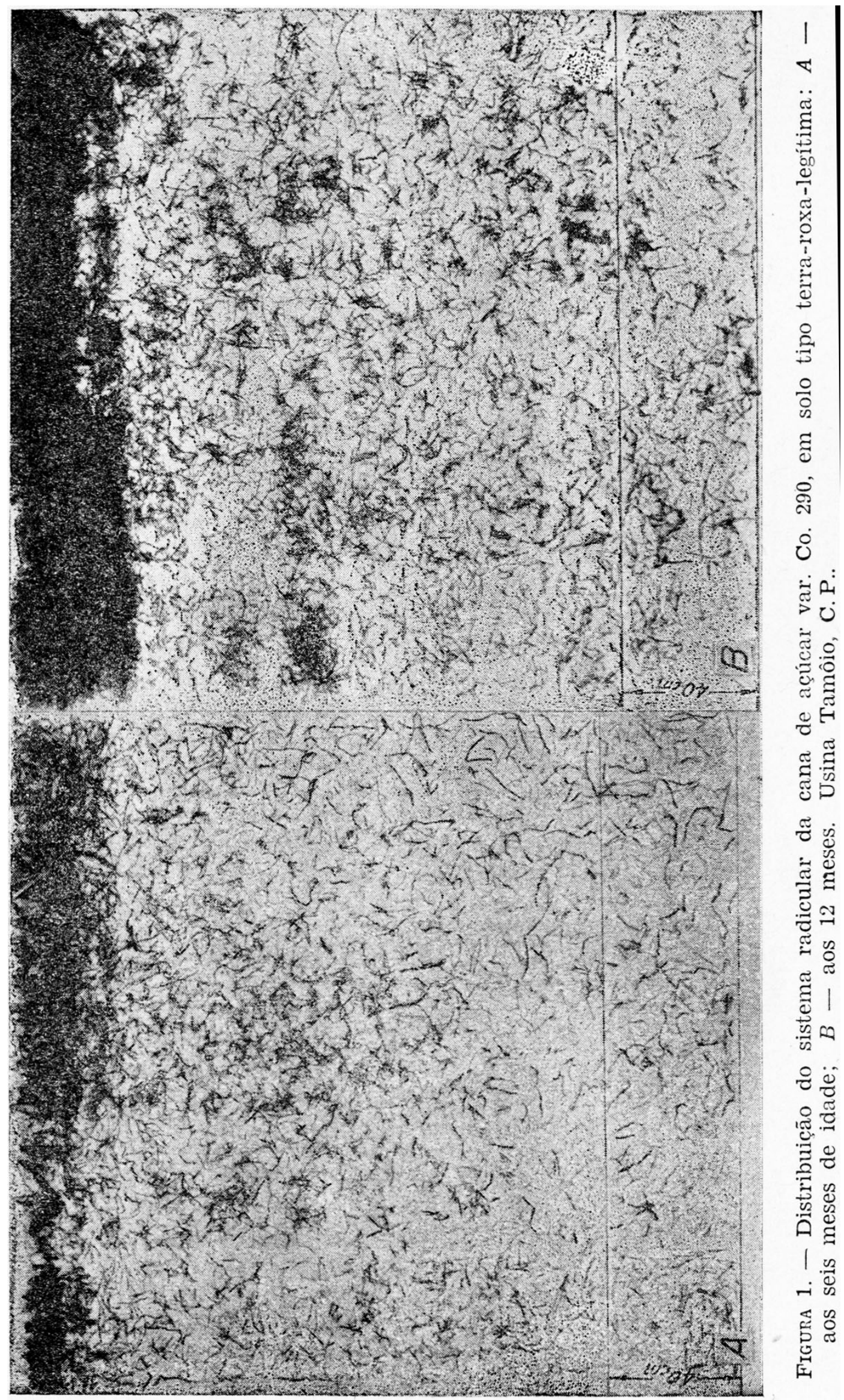


Os resultados mostram que as plantas apresentaram um grande aumento de raízes em relação à idade anterior, principalmente nas camadas superiores do solo, o que provàvelmente se deve não apenas à sua idade, mas, principalmente à maior umidade do solo neste período vegetativo da planta (quadro 1).

Os blocos de terra extraídos forneceram um total de $965,50 \mathrm{~g}$ de raízes. Nos primeiros $30 \mathrm{~cm}$ de profundidade encontraram-se $686,20 \mathrm{~g}$, correspondendo a $71,0 \%$, sendo que nos primeiros $20 \mathrm{~cm}$ foram encontradas $584,50 \mathrm{~g}$, o que representa $60,5 \%$ das raízes. Nas camadas abaixo de $30 \mathrm{~cm}$ os aumentos de raízes foram bem menores.

$O$ incremento verificado de 6 para 12 meses mostra que há uma estreita relação entre o desenvolvimento do sistema radicular e o crescimento da parte aérea. Êstes resultados confirmam os obtidos por Lee e Jensen, em estudos realizados nos solos de Hawaii e Cuba $(4,5)$.

Tomando-se por base o pêso total de raízes, em um hectare de terra foram encontradas 8 toneladas. Na quantidade de matéria orgânica fornecida ao solo pelas raízes e palhaça, complementada pela proteção à erosão que exerce esta planta, está a explicação para os sucessivos cultivos da cana que vêm sendo feitos há muitos anos pelas nossas usinas, sem o emprêgo de rotação de cultura. Ĵste fato já havia chamado a atenção de Lee, em seus estudos realizados no Hawai (5).

A figura 1- $B$ mostra a distribuição das raízes nas diferentes camadas do solo, até a profundidade de $2,10 \mathrm{~m}$.

\section{3 - SISTEMA RADICULAR AOS 18 MESES}

O terceiro e último estudo foi realizado em fins de agôsto, ocasião em que a cana está madura, pronta para o corte. Este período coincide novamente com a época sêca e relativamente fria.

Com a planta nesta idade os blocos de terra foram retirados do solo até onde não houvesse mais raízes, atingindo a profundidade de $3,30 \mathrm{~m}$, com um pêso total de $751,50 \mathrm{~g}$. O pêso total da parte aérea, para $2 \mathrm{~m}$ de linha, foi de $37,90 \mathrm{~kg}$, sendo $30,35 \mathrm{~kg}$ correspondentes aos colmos e $7,55 \mathrm{~kg}$, às pontas e palhas que ficaram no terreno. Êstes dados correspondem a uma produção de 100 toneladas de cana por hectare.

Neste último trabalho foram retirados 90 blocos de terra, sendo que os resultados dos 60 primeiros encontram-se no quadro 3. Êsses dados mostram que até a profundade de $2,10 \mathrm{~m}$ foram encontrados 706, $20 \mathrm{~g}$ de raízes, as quais correspondem a 5,9 toneladas por hectare. Nos primeiros $30 \mathrm{~cm}$ de solo o total de raízes foi de $466,00 \mathrm{~g}$, que correspondem a $66,0 \%$. 
Por êsses resultados verificou-se que o sistema radicular nessa idade foi menor em pêso do que aos 12 meses. Entretanto, neste último estudo foi encontrada uma certa quantidade de raízes mortas, a qual não foi computada em virtude de o estudo se restringir às raízes em atividade. Essa diferença está pràticamente nos primeiros $10 \mathrm{~cm}$ de solo, que passou de $404,00 \mathrm{~g}$ aos 12 meses para $168,00 \mathrm{~g}$ aos 18 , representando, respectivamente, $41,8 \%$ e $23,8 \%$ do total.

Observou-se uma modificação na proporção de raízes nas primeiras camadas de solo, do periodo de crescimento da planta para a idade da cana madura. Enquanto que aos 12 meses, em condições favoráveis de umidade no solo, nos primeiros $10 \mathrm{~cm}$ encontraram-se $41,8 \%$ de raízes e $18,7 \%$ nos $10 \mathrm{~cm}$ seguintes, na última idade, que corresponde a um período sêco, encontraram-se $23,8 \%$ e $29,5 \%$, respectivamente, para essas camadas. Êste aumento verificado abaixo dos primeiros $10 \mathrm{~cm}$ de solo, neste último estudo estendeu-se até a profundidade de $50 \mathrm{~cm}$.

Em estudos realizados com o sistema radicular da cana, Venkatraman e Thomas, citados por Jensen (4), relatam que "durante o estado adulto da cana-planta há quase que um contínuo desenvolvimento de novas raízes, resultando numa constante mudança do sistema radicular, o qual prontamente se adapta às condições do meio". Baseados principalmente nesta particularidade e influência da água $(2,8,9)$, as modificações havidas se devem ao dessecamento da camada superficial do solo, provocando uma readaptação do sistema radicular à procura de umidade em camadas mais profundas.

A figura 2 apresenta a distribuição das raízes neste estudo.

\section{4 - CONCLUSÕES}

Os resultados do estudo do sistema radicular da cana-planta, feito com a variedade Co. 290, para uma produção de 100 ton/ha, em condições normais de cultivo, em solo terra-roxa-legítima, permitiram tirar as seguintes conclusões.

a) O sistema radicular apresentou uma distribuição muito boa, pois a densidade de raízes nas diferentes camadas do solo decresceu gradativamente à medida que elas se aprofundavam no solo. Na cana-planta adulta as raízes chegaram a alcançar a profundidade de $3,30 \mathrm{~m}$, sendo que aos 6 meses já ultrapassavam de $2,10 \mathrm{~m}$.

b) O desenvolvimento das raízes aos 6 meses foi maior no sentido da profundidade, enquanto que dos 6 aos 12 meses apresentou um desenvolvimento muito maior nas primeiras camadas do solo. As plantas com 12 meses apresentaram o máximo de raízes 


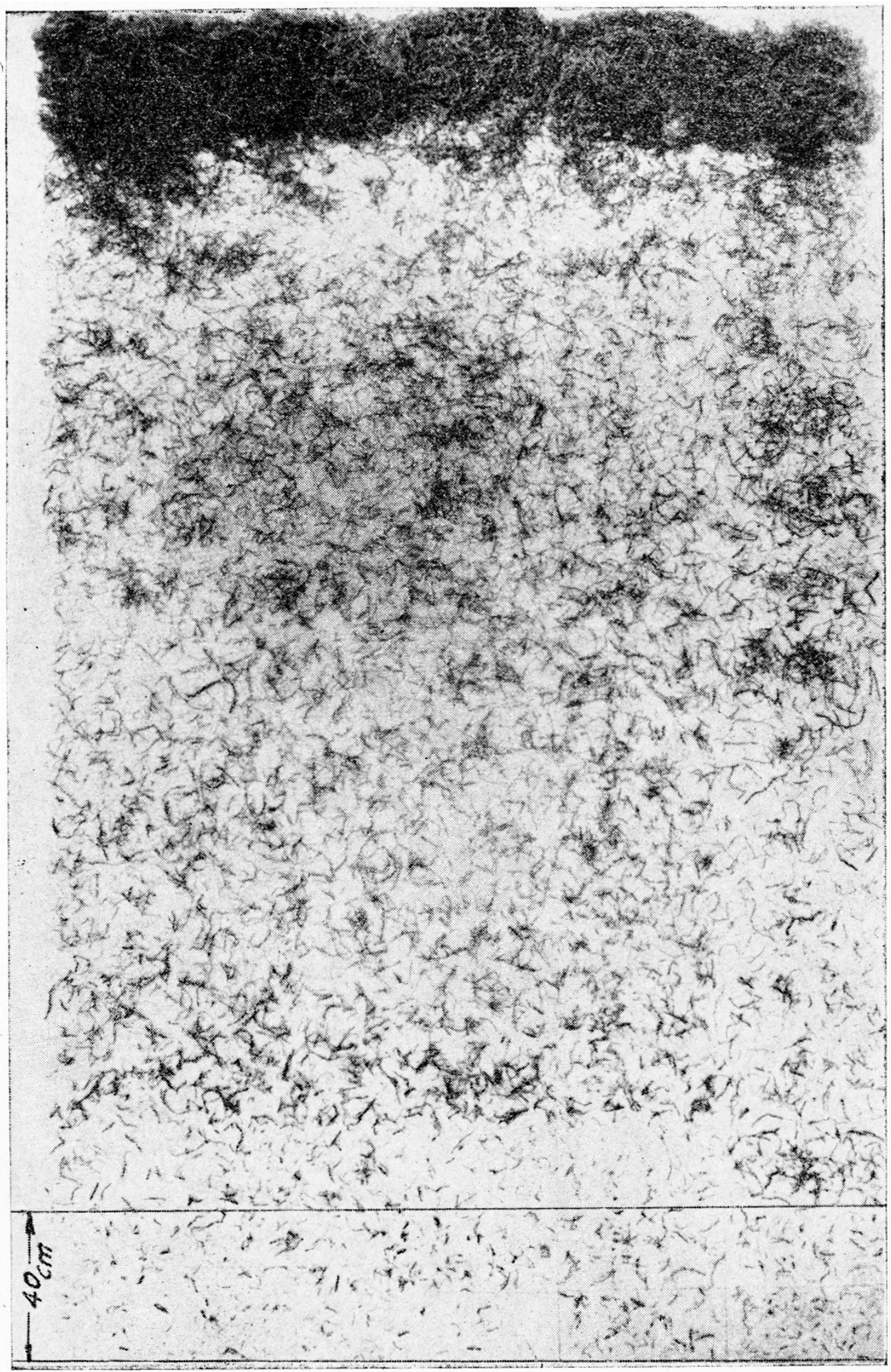

Figura 2. - Distribuição do sistema radicular da cana de açúcar var. Co. 290, em solo tipo terra-roxa-legítima, aos 18 meses de idade. Usina Tamôio, C.P.. 
em tôdas as camadas de solo. No estudo da cana madura, isto é, com 18 meses, encontrou-se uma pequena porcentagem de raízes mortas. Nesta última idade observou-se uma readaptação do seu sistema radicular às condições do meio.

c) Para um volume de terra correspondente a 2,0 $00,60 \times$ $2,10 \mathrm{~m}$, representando, respectivamente, comprimento, largura $\mathrm{e}$ profundidade, foram encontradas as seguintes quantidades de raízes em atividade: $215,10,965,50$ e $706,20 \mathrm{~g}$, respectivamente, para as idades de 6, 12 e 18 meses. As quantidades de raízes e suas porcentagens nos primeiros $30 \mathrm{~cm}$ de solo, para os três estudos, em ordem crescente de idade da planta, foram de 88,15, 686,20 e $466,00 \mathrm{~g}$, representando, respectivamente, $40,9,71,0$ e $66,0 \%$ do total. Portanto, a maior quantidade de raízes se acha localizada nos primeiros $30 \mathrm{~cm}$ de solo, com uma média (3 estudos) de 59,3\%.

d) A cana-planta forneceu ao solo cêrca de 8 toneladas de xaízes por hectare, distribuídas em diferentes profundidades, sendo que a maioria se encontra nos primeiros $30 \mathrm{~cm}$.

\section{ROOT DEVELOPMENT OF THE SUGAR CANE IN RED SOIL}

\section{S U M M A R Y}

Observations were made on the development of sugar cane roots (var. Co. 290) in red soil ("terra-roxa-legitima") at the Usina Tamoio, Araraquara. Root samples were taken from commercial sugar cane fields when they were 6, 12 and 18 months old.

The results showed that the distribution of the root system of the variety studied was uniform in the different layers of soil. Most roots were present in the upper $30 \mathrm{~cm}$ of soil, with an average for the 3 samplings of $59.3 \%$.

Roots of 6-month old plants already reached $2.10 \mathrm{~m}$, and after 18 months they reached as far as $3.30 \mathrm{~m}$. The maximum amount of living roots was found when the plants were 12 months old, this being correlated with the highest growth rate of the plant.

A sugar cane field that yields 100 tons per hectare was estimated to have about 1.8 tons of roots at 6 months and 8 tons of them after 18 months.

\section{LITERATURA CITADA}

1. Brasil. Ministério da Agricultura. Serviço de Estatística de Produção. Conselho Nacional de Estatística - I.B.G.E. Brasil, Produção agrícola, 1950-1954. 1954. 49 p. [Mimeografado]

2. DILLEWIJN, C. VAN. Botany of Sugarcane. Waltham, Mass., The Chronica Botanica Co., 1952. p. [123]-161.

3. FRANCO, C. M. \& INFORZATO, $R$. O sistema radicular do cafeeiro nos principais tipos de solos do Estado de São Paulo. Bragantia 6:[443]-478. 1946.

4. JENSEN, JAMES $H$. Some studies of root habits of sugar cane in Cuba. Yonkers, N. Y., Tropical Plant Research Foundation, 1951. 37 p. (Scientific Contribution $n .^{\circ}$ 21) 
5. LEE, H. A. The distribution of the roots of sugar cane in the soil in the Hawaiian Islands. Plant Physiol. 1:363-378. 1926.

6. PAIVA, J. E. (neto), CATANI, R. A., KUPPER, A. [e outros]. Observações gerais sôbre os grandes tipos de solos do Estado de São Paulo. Bragantia 11: [227]-253. 1951.

7. VENKATRAMAN, ROA SAFIB T. S. \& THOMAS, R. Studies of sugar cane roots at differents stages of growth. Mem. Dep. Agric. India, Bot. 16:145-157. 1929. [Original nāo consultado, citado em 4]

8. WEAVER, J. E. Root development of field crops. New York, McGraw-Hill Book Co., 1926. xii, 291 p.

9. —_ \& CLEMENTS, E. F. Ecologia Vegetal. (Trad. da 2. ${ }^{a}$ edição em inglês, por L. Cabrera Angel). Buenos Aires, Acme Agency, 1950. p. 325-375. 